\title{
Density and nutritional condition of carabid beetles in wildflower areas of different age
}

\author{
Thomas Frank $^{\mathrm{a}, *}$, Patrik Kehrli ${ }^{\mathrm{b}, 1}$, Christoph Germann ${ }^{\mathrm{b}}$ \\ ${ }^{\text {a } U n i v e r s i t y ~ o f ~ N a t u r a l ~ R e s o u r c e s ~ a n d ~ A p p l i e d ~ L i f e ~ S c i e n c e s, ~ D e p a r t m e n t ~ o f ~ I n t e g r a t i v e ~ B i o l o g y ~ a n d ~ B i o d i v e r s i t y ~ R e s e a r c h, ~}$ \\ Institute of Zoology, Gregor Mendel Straße 33, A-1180 Vienna, Austria \\ ${ }^{\mathrm{b}}$ Zoological Institute, University of Bern, Baltzerstrasse 6, CH-3012 Bern, Switzerland
}

\begin{abstract}
Density and nutritional condition of the five carabid beetle species Agonum mülleri, Anchomenus dorsalis, Anisodactylus binotatus, Pterostichus vernalis and Poecilus cupreus was studied. Carabids were caught in sixteen 1-4-year-old wildflower areas, identified and counted, their nutritional condition was calculated and calculations were related to habitat parameters (i.e. wildflower area age, vegetation cover, soil water content, habitat size, surrounding landscape composition) and sex.

Whereas the number of Anisodactylus binotatus caught responded positively to succession in wildflower areas, A. mülleri numbers tended to decrease and the other three species were unaffected. In a stepwise multiple regression species affiliation, sex and age of wildflower area explained together $98.5 \%$ of the variance in the pooled nutritional condition of Anchomenus dorsalis, Anisodactylus binotatus, A. mülleri and $P$. vernalis. Age of wildflower area alone explained $61.7 \%$ of the variance and age increased the nutritional condition of carabids. Correspondingly, nutritional condition of Poecilus cupreus was positively correlated with the age of wildflower area. Overall, the nutritional condition of the carabid assemblage studied increased from the first to the second year and then remained stable. To keep the proportion of 1year-old wildflower areas low, wildflower areas should therefore be maintained for several years to improve the life conditions of carabid beetles and to enhance their beneficial effects in agroecosystems.
\end{abstract}

Keywords: Agonum mülleri; Anchomenus dorsalis; Anisodactylus binotatus; Poecilus cupreus; Pterostichus vernalis; Semi-natural habitats

\section{Introduction}

Predatory insects are often food limited under field conditions (Pearson and Knisley, 1985; Bommarco, 1998a). However, a substantial resource uptake is vital for adults because a major part of these resources is used for reproduction (Wise, 1979; Juliano, 1986). Egg production of the carabid beetle Poecilus cupreus Linnaeus was shown to be positively related to food intake of adult beetles (Bommarco, 1998b). Thus, beetles with access to habitats with larger

\footnotetext{
* Corresponding author. Tel.: +43147654 3201; fax: +431476543203. E-mail address: thomas.frank@boku.ac.at (T. Frank).

${ }^{1}$ Present address: Unit of Ecology and Evolution, Department of Biology, University of Fribourg, Ch. du Musée 10, CH-1700 Fribourg, Switzerland.
}

amount of food should be of better constitution and therefore produce more offspring. Overall, food quantity and quality may affect fitness and population dynamics in arthropod communities of agroecosystems (Wallin et al., 1992; Bommarco, 1999; Östman, 2005). Nutritional condition is therefore a sensitive measure that reflects constitution and reproductive potential of insects and incorporates abiotic and biotic environmental factors. In consequence, nutritional condition and population density are considered to be good indicators to assess habitat quality (van Dijk, 1983; Sota, 1985).

Many ground beetles are polyphagous predators commonly found in arable crops. They are important natural control agents of agricultural pests (Bohan et al., 2000; Thomas et al., 2001; Symondson et al., 2002; Holland et al., 2005). Carabids have been shown to be affected by the 
occurrence of semi-natural habitats in agricultural land (Kromp, 1999; Purtauf et al., 2005a), e.g. wildflower areas (Lys et al., 1994; Zangger et al., 1994; Frank, 1997). Wildflower areas (a term synonymous with wildflower or weed strips) are man-made habitats, designed to enhance overall arthropod diversity. They have been gradually introduced into the European agricultural landscape over the last decade (Nentwig, 2000). Typically, wildflower areas are sown either inside fields or along their edges and are maintained up to 6 years, thereby passing through the early stages of secondary succession. Yet, only Barone and Frank (2003) examined the effect of the succession in wildflower areas on the nutritional condition of predators. Their findings showed that the carabid Poecilus cupreus responded positively to habitat age.

The present investigation is an extension of the above cited study and aims for generalising its findings. It therefore investigates numerical, physiological and ecological features of a carabid assemblage. The study investigated Agonum mülleri Herbst, Anchomenus dorsalis Pont., Anisodactylus binotatus Fabr., Pterostichus vernalis Panz. and also Poecilus cupreus, the five most abundant polyphagous spring breeding carabid beetles observed in the 1-4-year-old wildflower areas investigated (Mosimann, 2002). It might be expected that density and nutritional condition of these predatory carabids would increase with the age of wildflower areas due to higher structural complexity (Günter, 2000), increased prey abundance (Künzle, 2002) and extensive farming practices applied. The present study examines the influence of habitat factors on carabid activity density and nutritional condition. Furthermore, activity density and nutritional condition allow for exploring intraspecific and interspecific competition amongst these carabid beetles, which has, to our knowledge, never been explored before in semi-natural habitats of agroecosystems. This is important because predator interference such as competition and intraguild predation can diminish pest control by these beneficials (Müller and Brodeur, 2002). In the present study the nutritional condition is expressed by a condition factor.

The main objective of this investigation was to answer the following questions:

1. Do condition factor and activity density of common field carabids respond to age of wildflower area across an early successional gradient in 1-4-year-old wildflower areas?

2. Which habitat factors affect condition factor and activity density of carabid beetles in 1-4-year-old wildflower areas?

3. Are there any signs of intra- or inter-specific competition between the condition factor and activity density of carabids?

\section{Materials and methods}

The investigation was conducted at 16 study sites in the Swiss plateau around Bern, across a region measuring approximately $20 \mathrm{~km} \times 23 \mathrm{~km}$. In 2001, 1-4-year-old wildflower areas (four replicates each) were investigated. The wildflower areas ranged from 0.19 to 3.50 ha with a mean size of 0.76 ha. All wildflower areas were adjacent to crop fields and established on land in which cereals were the previous crops. Wildflower areas were neither cut nor grazed, and no fertilizer and pesticides were applied. The selected wildflower areas did not significantly differ in size (ANOVA: $F_{3,15}=1.921, p=0.180$ ) and surrounding landscape composition (ANOVA: $F_{3,15}=0.656, p=0.594$ ) among the four successional stages. The minimum distance between two sites was $500 \mathrm{~m}$ and wildflower areas were selected to be located in the same climate zone providing similar site conditions in terms of altitude, mean annual rainfall and temperature. The wildflower areas were sown by farmers in April between 1998 (4-year-old) and 2001 (1year-old wildflower areas) using a standard wildflower mixture containing 25 herbaceous species (Günter, 2000). Pitfall traps ( $7 \mathrm{~cm}$ opening diameter, half filled with $4 \%$ formaldehyde plus $0.5 \%$ detergent) were set up in wildflower areas to assess the activity density of the carabid beetles. On 10 May 2001 a row of five traps was set in the centre of each wildflower area and traps were placed approximately $20 \mathrm{~m}$ apart. Traps were emptied fortnightly between 24 May and 2 July 2001 and carabids collected were stored in $70 \%$ ethanol. A total of 1501 specimens of $A$. mülleri, A. dorsalis, A. binotatus, $P$. vernalis and $P$. cupreus were examined. Sampling period corresponded to the main period of activity and reproduction of these five spring breeding carabid beetles.

The condition factor of $P$. cupreus was investigated in a previous study (Barone and Frank, 2003). Prior to biomass measurement, $P$. cupreus was put on blotting paper for $1 \mathrm{~min}$ at room temperature and weighed on a sensitive set of scales (accuracy $0.01 \mathrm{mg}$ ) to assess its fresh weight. Thereafter, the length of the beetles' left elytra, which provides a good indicator of body size (Juliano, 1986; Nelemans, 1987), was measured under a binocular microscope. To assess the nutritional condition ("fatness") of the beetles, a condition factor was calculated for each individual (Le Cren, 1951; Juliano, 1986). This condition factor is based on the relationship between body weight $(W)$ and elytra length $(L)$ expressed by the formula $W=a L^{b}$, where $a$ and $b$ are constants. The weights of all beetles were plotted against their own length and the constants $a$ and $b$ of the power regression curve $\left(y=a x^{b}\right)$ were determined. Afterwards, the condition factor $(\mathrm{CF})$ was calculated for each beetle $(i)$ using the formula $\mathrm{CF} i=W i /(\mathrm{Li})^{b}$. At a later date, A. mülleri, A. dorsalis, $A$. binotatus and $P$. vernalis were treated analogously except that specimens were dried for $24 \mathrm{~h}$ at $50{ }^{\circ} \mathrm{C}$ to assess their dry weight. Even though fresh weight and dry weight are correlated (Barone and Frank, 2003), dry weight is a more reliable measure to calculate the condition factor. The improved procedure, however, produced considerably different condition factors for these four species and $P$. cupreus. 
Previous studies showed that the habitat factors vegetation cover, soil water content, surrounding landscape composition and habitat size are important for the distribution of epigeic predatory beetles in agroecosystems (Bohac et al., 1999; Mosimann, 2002; Frank and Reichhart, 2004; Purtauf et al., 2005b). These factors were therefore quantified in the present study assuming that they may be of explanatory value for the variability of the condition factor of carabid beetles in wildflower areas. The proportion of vegetation covering the surface was estimated over the whole sampling period on three occasions at six randomly chosen places $(25 \mathrm{~cm} \times 25 \mathrm{~cm})$ per site and averaged over time. Percentage soil water content was measured on one occasion per study site by taking eight measurements with a TDR-probe (supplier: DMP AG, Fehraltorf, Switzerland) at randomly chosen places. To estimate the surrounding landscape composition, the percentage of 'semi-natural habitat composition' (e.g. extensively managed meadows, sown wildflower areas, ruderal areas, orchards, hedges, forest and single trees) was measured at a radius of $150 \mathrm{~m}$ around each site. A $150 \mathrm{~m}$ presented a sound compromise between labour available for assessing the semi-natural habitat composition and the spatial scale at which carabids encounter the surrounding landscape (Purtauf et al., 2005a). Habitat size was estimated by measuring the length and width of each study site.

For data analyses, the mean condition factor of a species' sex, which corresponds to an average value over time, was calculated for each of the sixteen wildflower areas. Looking for general responses of the carabid assemblage, stepwise multiple regression analysis was used to study the influence of the independent variables age of wildflower area (age), vegetation cover, soil water content, habitat size, surrounding landscape composition, carabid beetle species and sex on the dependent variables condition factor and activity density (AD). Whereas age of wildflower area, vegetation cover, soil water content, habitat size and surrounding landscape composition presented continuous measures, carabid beetle species and sex were treated as categorical variables. The variables sex and species were therefore binary dummy coded where males and A. mülleri served as bases of calculation. However, because the nutritional condition of $P$. cupreus was based on its fresh weight pooling with the other carabid species was awkward and its condition factor was therefore analysed on its own. In addition, the five species were analysed individually to receive also species-specific responses of the nutritional condition and the activity density to the succession in wildflower areas. Thus, curve estimation regression models of SPSS 12.0.1 were used to fit a relationship between the age of wildflower areas and the condition factors as well as the activity density.

Exploring intraspecific and interspecific competition amongst carabids, the condition factor of a species' sex was correlated with the number of same-sex conspecifics, conspecifics and the four other species present in a study site by using single linear regressions. The fulfilment of model assumptions was checked by visual inspection of the residual's distribution for all statistical tests conducted.

\section{Results}

Poecilus cupreus accounted for more than half of the 1501 specimens examined, followed by the much less frequent $A$. mülleri, A. binotatus, A. dorsalis and P. vernalis (Table 1). Stepwise multiple regression on the latter four species revealed that the independent variables age of wildflower area, species and sex explained $98.5 \%$ of the variance of their pooled condition factors (Table 2). The remaining of the carabid species in the regression model indicated that there were significant differences between the species tested. The condition factor of A. binotatus was generally higher than the one of A. mülleri whereas the other two species had a lower condition factor. Furthermore, females generally had a higher condition factor than males. The positive slope of age of wildflower area signified that the condition factor of beetles increased with the age of the wildflower area (Table 2). It was considerably lower in 1-year-old than in 2-4-year-old wildflower areas, indicating that newly established wildflower areas were of less value for carabid nutrition (Fig. 1). Testing for species-specific responses, analysis showed that females of A. binotatus $\left(\mathrm{CF}=\mathrm{e}^{3.08-(0.21 / \text { age })}, R^{2}=0.30, F_{1,14}=6.08\right.$, $p=0.027)$ and males of $A$. dorsalis $\left(\mathrm{CF}=\mathrm{e}^{1.13-(0.12 / \text { age })}\right.$, $\left.R^{2}=0.27, F_{1,13}=4.75, p=0.048\right)$ reacted positively to the

Table 1

Identity and number of individuals of carabid beetles investigated

\begin{tabular}{|c|c|c|c|c|c|c|}
\hline Sex & $\begin{array}{l}\text { Age of wildflower } \\
\text { area }\end{array}$ & $\begin{array}{l}\text { Anisodactylus } \\
\text { binotatus }\end{array}$ & $\begin{array}{l}\text { Poecilus } \\
\text { cupreus }\end{array}$ & $\begin{array}{l}\text { Anchomenus } \\
\text { dorsalis }\end{array}$ & $\begin{array}{l}\text { Agonum } \\
\text { mülleri }\end{array}$ & $\begin{array}{l}\text { Pterostichus } \\
\text { vernalis }\end{array}$ \\
\hline \multirow[t]{4}{*}{ Females } & 1 & 8 (4) & $82(4)$ & $21(3)$ & $81(4)$ & $6(1)$ \\
\hline & 2 & $19(4)$ & 94 (4) & $15(4)$ & $13(3)$ & $20(3)$ \\
\hline & 3 & $51(4)$ & $106(4)$ & $31(4)$ & $26(4)$ & 39 (4) \\
\hline & 4 & $30(4)$ & $91(4)$ & 9 (4) & $11(3)$ & $13(4)$ \\
\hline \multirow[t]{4}{*}{ Males } & 1 & $0(0)$ & $86(4)$ & $27(4)$ & $59(2)$ & $8(2)$ \\
\hline & 2 & $20(3)$ & 109 (4) & $29(4)$ & 7 (2) & $21(3)$ \\
\hline & 3 & $35(4)$ & 108 (4) & $29(4)$ & $13(3)$ & 31 (4) \\
\hline & 4 & 39 (4) & 87 (4) & $10(3)$ & $6(3)$ & $11(4)$ \\
\hline
\end{tabular}

The number in parentheses specifies the number of wildflower areas in which a species' sex was present. 


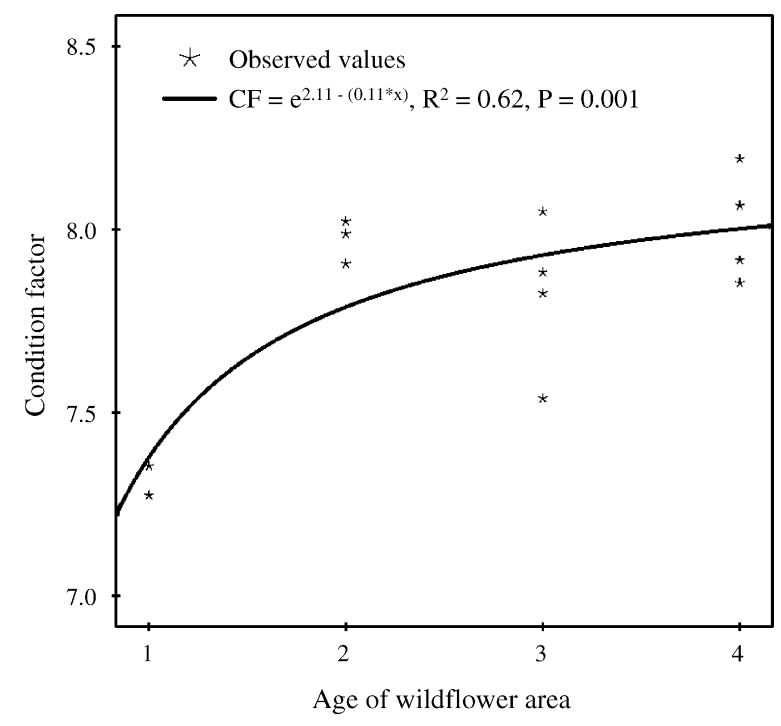

Fig. 1. Relationship between the condition factor of study sites with Agonum mülleri, Anchomenus dorsalis, Anisodactylus binotatus and Pterostichus vernalis present and age of wildflower area. P. vernalis was absent from two 1- and one 2-year-old wildflower areas.

age of the wildflower areas. The condition factor of $P$. vernalis males $\quad\left(\mathrm{CF}=\mathrm{e}^{1.28-(0.09 / \text { age })}, \quad R^{2}=0.29, \quad F_{1,11}=4.50\right.$, $p=0.057)$ tended to increase whereas the other species' sexes did not respond to age of wildflower area. Likewise, the condition factor of $P$. cupreus was significantly affected by sex, age of wildflower area and soil water content (Table 2). The stepwise multiple regression model explained $98.3 \%$ of the variance and males of $P$. cupreus had a significantly higher condition factor than females. Even so, both sexes responded positively to the age of wildflower areas (females: $\mathrm{CF}=\mathrm{e}^{-0.27-(0.17 / \text { age })}, R^{2}=0.77, F_{1,14}=46.24, p<0.001$; males: $\quad C F=\mathrm{e}^{0.09-(0.10 / \text { age })}, \quad R^{2}=0.79, \quad F_{1,14}=52.16$, $p<0.001)$.

Seeking for a general response of carabid activity density to habitat factors, the number of individuals per sex of the

Table 2

Stepwise multiple regression on the dependence of the condition factor of (a) Agonum mülleri, Anchomenus dorsalis, Anisodactylus binotatus and Pterostichus vernalis pooled and (b) Poecilus cupreus upon habitat factors, sex and carabid species

\begin{tabular}{lrrr}
\hline Explaining variable & Slope & $t$-Value & $p$-Value \\
\hline (a) Intercept & & 52.44 & $<0.001$ \\
Sex & 0.253 & 15.07 & $<0.001$ \\
Anisodactylus binotatus & 1.212 & 50.33 & $<0.001$ \\
Anchomenus dorsalis & -0.420 & -17.88 & $<0.001$ \\
Pterostichus vernalis & -0.333 & -13.50 & $<0.001$ \\
Age of wildflower area & 0.019 & 2.48 & 0.015 \\
(b) Intercept & & -3.09 & 0.005 \\
Sex & -0.388 & -39.50 & $<0.001$ \\
Age of wildflower area & 0.023 & 4.47 & 0.001 \\
Soil water content & 0.007 & 2.63 & 0.014 \\
\hline
\end{tabular}

Sex (base $=$ male) and species (base $=$ A. mülleri) were dummy coded. (a) Residual S.E.: 0.086, multiple $R^{2}: 0.985, F_{5,100}: 1353$, $p$-value $<0.001$; (b) residual S.E.: 0.028 , multiple $R^{2}: 0.983, F_{3,28}: 538.5, p$-value $<0.001$.
5 species present in the 16 study sites was also analysed with stepwise multiple regression. Besides the categorical species identity of $P$. cupreus no other term remained in the reduced model $\left(\mathrm{AD}=5.77+18.08\right.$ Poecilus cupreus, $R^{2}=0.49$, $\left.F_{1,158}=153.8, p<0.001\right)$. This outcome pointed at species-specific effects of succession on activity density. The five carabid species were therefore also analysed on their own. The age of wildflower area had a positive effect on the number of A. binotatus of both sexes (females: $\mathrm{AD}=2.17+5.761$ n(age), $R^{2}=0.36, F_{1,14}=7.77, p=0.015$; males: $\mathrm{AD}=0.07$ $+7.31 \ln ($ age $\left.), R^{2}=0.68, F_{1,14}=30.00, p<0.001\right)$ and tended to decrease the activity density of $A$. mülleri (females: $\mathrm{AD}=17.58-11.82 \ln ($ age $), R^{2}=0.23, \quad F_{1,14}=4.21, \quad p=$
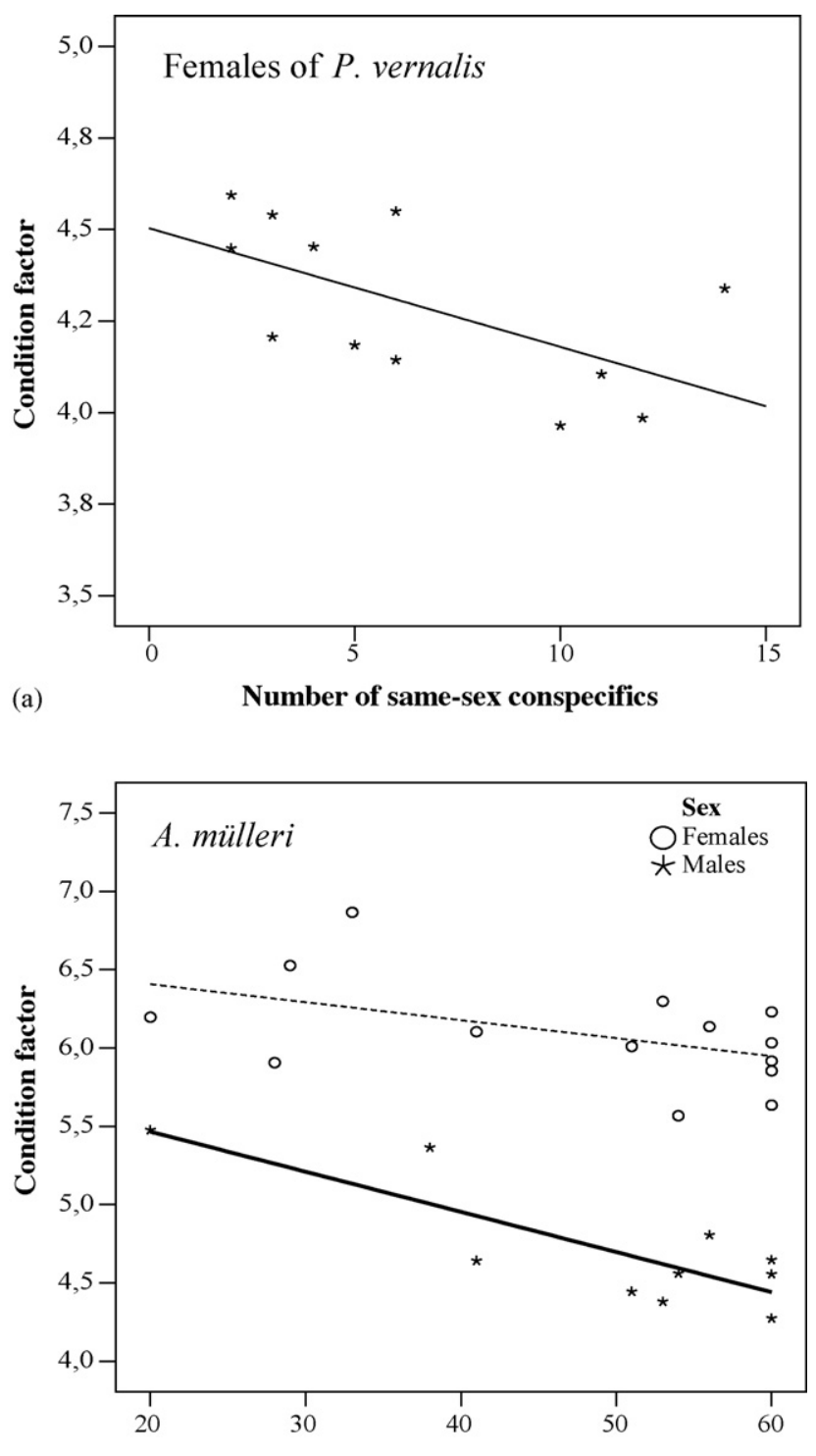

(b)

Number of $P$. cupreus

Fig. 2. Relationship between the condition factor of (a) Pterostichus vernalis females and the number of conspecific females $(\mathrm{CF}=4.50-0.32 x$, $R^{2}=0.37, F_{1,10}=5.85, p=0.036$ ), (b) female Agonum mülleri and the number of Poecilus cupreus $\left(\mathrm{CF}=6.64-0.01 x, R^{2}=0.24, F_{1,12}=3.75\right.$, $p=0.077)$ and male A. mülleri and the number of $P$. cupreus in wildflower areas $\left(\mathrm{CF}=5.98-0.03 x, R^{2}=0.67, F_{1,8}=16.44, p=0.004\right)$. 
0.059; males: $\mathrm{AD}=12.66-9.24 \ln ($ age $), \quad R^{2}=0.25$, $\left.F_{1,14}=4.60, p=0.050\right)$. The activity density of the other three species was unaffected by the age of wildflower area.

The exploration of intraspecific and interspecific competition amongst carabids revealed that the condition factor of $P$. vernalis females responded negatively to the number of conspecific females (Fig. 2a), however, P. vernalis males were not affected by any form of intra- or inter-specific competition. The condition factor of A. mülleri males was significantly decreased by the presence of $P$. cupreus, and also females of $A$. mülleri tended to be negatively affected by $P$. cupreus (Fig. 2b). However, the condition factor of $P$. cupreus was not affected by the presence of $A$. mülleri (females: $\mathrm{CF}=0.71-0.001$ age, $R^{2}=0.16, F_{1,14}=2.72$, $p=0.121$; males: $\quad \mathrm{CF}=1.05-0.001$ age, $\quad R^{2}=0.17$, $\left.F_{1,14}=2.82, p=0.115\right)$. Besides, there was no evidence for intraspecific or interspecific competition in the carabid assemblage examined.

\section{Discussion}

In contrast to plant communities (e.g. Tilman, 1990; Bazzaz, 1996) few studies have considered successional processes in insect communities. According to Brown and Hyman (1986) and Brown and Southwood (1987) an increase in overall insect species diversity may be expected with successional age of habitat. Even though in the present study it was not tested for species diversity, the results confirm that succession in wildflower areas increased the nutritional condition of beetles, which may result in enhanced reproductive potential (van Dijk, 1994; Bommarco, 1998b; Barone and Frank, 2003). However, the study also showed that succession in wildflower areas affected the density of carabid species differently.

On the community level, Siemann et al. (1999) observed an increase in arthropod diversity in abandoned agricultural fields with progressing successional age. In the present study, the number of $A$. binotatus responded positively to succession in wildflower area, whereas A. mülleri numbers tended to decrease with age. However, succession had no effect on the activity density of the other three species analysed. Anisodactylus binotatus is known to be associated with more or less densely vegetated fields (Marggi, 1992), and vegetation cover in wildflower areas was shown to increase with successional age (Günter, 2000). Moreover, this beetle feeds on animal and also plant material (Koch, 1989) whose biomass increases with the age of wildflower area (Günter, 2000). By contrast, A. mülleri was observed to prefer sparsely vegetated arable fields (Marggi, 1992), which explains its decrease with increasing wildflower area age.

The nutritional condition of all five carabid species examined increased with age of wildflower area. The condition factor of the carabid assemblage increased mainly from the first to the second year. From the second year onwards wildflower areas provided optimal conditions resulting in carabid constitution that was not further affected by the subsequent succession. Newly established wildflower areas do not yet have the structural complexity typical for older areas. It is therefore likely that spring carabids do not perceive the newly sown wildflower areas differently from surrounding habitats. The establishment of new wildflower areas takes time (Günter, 2000) and the first stages after sowing are normally characterised by fairly open ground. In fact, the soil surfaces in the youngest wildflower areas were barely covered by plants in the first weeks after sowing, implying considerable diurnal microclimate fluctuations in these habitats. Scarcely covered ground is accompanied by reduced supply of shelter and food for carabid beetles colonizing newly established wildflower areas (Powell et al., 1985; Marshall et al., 2003). The low condition factor of carabids present in the 1-year-old wildflower areas implicates that prey was scarce. This conclusion is strongly supported by the findings of Künzle (2002), who investigated the heteropteran bug and spider community in the same sixteen 1-4-year-old wildflower areas. Künzle (2002) found that the respective biomass of these two potential prey communities of carabids was significantly lower in 1-yearold wildflower areas than in 2-4-year-old areas. This pattern of prey abundance corresponds to that of the condition factor of carabids in wildflower areas. Consequently, an increased food supply in 2-4-year-old wildflower areas may have influenced the condition factor of $A$. binotatus, $A$. dorsalis, A. mülleri, $P$. vernalis and $P$. cupreus. Consistently, Denys and Tscharntke (2002) found that populations of predators as well as predator-prey ratios were significantly lower in 1year-old than in 6-year-old field margin strips. Higher prey abundance in older wildflower areas may be caused by higher structural complexity (Günter, 2000) as well as by the lack of pesticide use and the extensive mechanical methods allowed, e.g. no tillage and restricted cutting. However, the extensive farming practices applied may also affect carabid beetles directly due to reduced soil disturbance and greater weed diversity (Kromp, 1999). In addition, carabids may also be poorly nourished in 1-year-old wildflower areas because colonizers had to bear the energetic costs of longdistance walking (Lipp et al., 2005).

The high explanatory values of the dummy coded variables species and sex in the multiple regression model for A. mülleri, A. dorsalis, A. binotatus and P. vernalis are not surprising, as the condition factor of the four carabid species varies considerably. Within each species females tend to have a higher condition factor than males. The waterstoring capacity of the soil has been shown to be an important factor for carabid distribution in arable land (Holopainen et al., 1995) and correspondingly the nutritional condition of $P$. cupreus increased with soil water content. A higher soil water content allows for the growth of a denser vegetation, which provides more shelter and increases prey of arthropod predators (Powell et al., 1985; Marshall et al., 2003). 
Data indicate the occurrence of intraspecific and interspecific competition in the carabid assemblage studied. The negative relation between the condition factor of female $P$. vernalis and the activity density of conspecific females reveals gender related intraspecific competition, i.e. the more female conspecifics present the lower the condition factor of females. Regulation of densities by intraspecific competition is a well-known phenomenon for Coleoptera (e.g. Sato et al., 2004; Alves-Costa and Knogge, 2005). The condition factor of $A$. mülleri was significantly decreased with increasing numbers of $P$. cupreus. However, $P$. cupreus was only marginally affected by $A$. mülleri, which indicates an asymmetric interspecific competition among these two predatory beetles (Thiele, 1977). It appears that these species competed for similar resources, and that the larger $P$. cupreus had an adverse effect on the constitution of $A$. mülleri. These findings are, to our knowledge, the first quantitative indications of predator interference in seminatural habitats of agroecosystems.

Augmented food supply increased the reproductive potential of two carabid species (van Dijk, 1994; Bommarco, 1998b). Moreover, P. cupreus produced significantly more eggs in 4-year-old wildflower areas than in 1-year-old areas as a consequence of its nutritional condition (Barone and Frank, 2003). Thus, it may be expected that many carabid beetles produce more offspring in older wildflower areas, which may lead to higher predator densities in adjoining arable crops thereby increasing pest suppression. An overall beneficial effect of epigeic predators such as carabid beetles on pest control of aphids was observed by Schmidt et al. (2003). Additionally, ground-living predators of aphid pests increased barley yields in Sweden measurably (Östman et al., 2003). Moreover, parasitism of the rape pollen beetle was significantly higher in rape fields adjacent to 6-year-old than 1-year-old margin strips (Thies and Tscharntke, 1999). All these observations emphasize the importance of the age of semi-natural habitats for natural enemies and their potential for biological control in agroecosystems. As wildflower areas were shown to enhance the nutritional condition of carabid beetles as soon as the second year, it is recommended to maintain wildflower areas for several years so that in a given landscape the proportion of 1-year-old wildflower areas is low. Since most carabids of arable land are considered beneficials (e.g. Holland et al., 2005) this recommendation is of practical relevance in order to increase the beneficial effects of these generalist predators in agroecosystems.

\section{Acknowledgements}

The authors thank S. Frank for critical comments on the manuscript and for correcting the English. Further thanks to C. Mosimann who collected the beetles in the field. T. Frank was financially supported by the Austrian Science Fund (FWF, project number P16972-B12), and C. Germann was paid by the Hochschulstiftung an der Universität Bern.

\section{References}

Alves-Costa, C.P., Knogge, C., 2005. Larval competition in weevils Revena rubiginosa (Coeloptera: Curculionidae) preying on seeds of the palm Syagrus romanzoffiana (Arecaceae). Naturwissenschaften 92, 265-268.

Barone, M., Frank, T., 2003. Habitat age increases reproduction and nutritional condition in a generalist arthropod predator. Oecologia $135,78-83$.

Bazzaz, F.A., 1996. Plants in Changing Environments: Linking Physiological, Population, and Community Ecology. Cambridge University Press, Cambridge.

Bohac, J., Jedlicka, P., Frouz, J., 1999. Changes in communities of staphylinid beetles (Coleoptera, Staphylinidae) during secondary succession in abandoned fields. In: Proceedings of the Fifth Central European Workshop on Soil Zoology, Cesce Budejovice, April 27-30, pp. 19-25.

Bohan, D.A., Bohan, A.C., Glen, D.M., Symondson, W.O.C., Wiltshire, C.W., Hughes, L., 2000. Spatial dynamics of predation by carabid beetles on slugs. J. Anim. Ecol. 69, 367-379.

Bommarco, R., 1998a. Reproduction and energy reserves of a predatory carabid beetle relative to agroecosystem complexity. Ecol. Appl. 8, 846853.

Bommarco, R., 1998b. Stage sensitivity to food limitation for a generalist arthropod predator. Environ. Entomol. 27, 863-869.

Bommarco, R., 1999. Feeding reproduction and community impact of a predatory carabid in two agricultural habitats. Oikos 87, 89-99.

Brown, V.K., Hyman, P.S., 1986. Successional communities of plants and phytophagous Coleoptera. J. Ecol. 74, 963-975.

Brown, V.K., Southwood, T.R.E., 1987. Secondary succession: patterns and strategies. In: Gray, A.J., Crawley, M.J., Edwards, D.J. (Eds.), Colonization, Succession and Stability. Blackwell, Oxford, pp. 315-337.

Denys, C., Tscharntke, T., 2002. Plant-insect communities and predatorprey ratios in field margin strips, adjacent crop fields, and fallows. Oecologia 130, 315-324.

van Dijk, T.S., 1983. The influence of food and temperature on the amount of reproduction in carabid beetles. In: Brandmayer, P., den Boer, P.J., Weber, F. (Eds.), The Synthesis of Field Study and Laboratory Experiment. Report of the Fourth Meeting of European Carabidologists. pp. 105-123.

van Dijk, T.S., 1994. On the relationship between food, reproduction and survival of two carabid beetles: Calathus melanocephalus and Pterostichus versicolor. Ecol. Entomol. 19, 263-270.

Frank, T., 1997. Species diversity of ground beetles (Carabidae) in sown weed strips and adjacent fields. Biol. Agric. Hortic. 15, 297-307.

Frank, T., Reichhart, B., 2004. Staphylinidae and Carabidae overwintering in wheat and sown wildflower areas of different age. B. Entomol. Res. 94, 209-217.

Günter, M., 2000. Anlage und Pflege von mehrjährigen Buntbrachen unter den Rahmenbedingungen des schweizerischen Ackerbaugebietes. Agrarökologie 37, 1-154.

Holland, J.M., Thomas, C.F.G., Birkett, T., Southway, S., Oaten, H., 2005. Farm-scale spatiotemporal dynamics of predators beetles in arable crops. J. Appl. Ecol. 42, 1140-1152.

Holopainen, J.K., Bergmann, T., Hautala, E.-L., Oksanen, J., 1995. The ground beetle fauna (Coleoptera: Carabidae) in relation to soil properties and foliar fluoride content in spring cereals. Pedobiologia 39, 193206.

Juliano, S.A., 1986. Food limitation of reproduction and survival for populations of Brachinus (Coloeptera: Carabidae). Ecology 67, $1036-1045$.

Koch, K., 1989. Die Käfer Mitteleuropas. Ökologie. Band 1. Goecke \& Evers, Krefeld.

Kromp, B., 1999. Carabid beetles in sustainable agriculture: a review on pest control efficacy, cultivation impacts and enhancement. Agric. Ecosys. Environ. 74, 187-228.

Künzle, I., 2002. Early succession of bug communities (Insecta: Heteroptera) on wildflower areas. Diploma Thesis. University of Bern. 
Le Cren, E.D., 1951. The length-weight relationship and seasonal cycle in gonad weight and condition in the perch (Perca fluviatilis). J. Anim. Ecol. 20, 201-219.

Lipp, A., Wolf, H., Lehmann, F.O., 2005. Walking on inclines: energetics of locomotion in the ant Camponotus. J. Exp. Biol. 208, 707-719.

Lys, J.-A., Zimmermann, M., Nentwig, W., 1994. Increase in activity density and species number of carabid beetles in cereals as a result of strip-management. Entomol. Exp. Appl. 73, 1-9.

Marggi, W., 1992. Faunistik der Sandlaufkäfer und Laufkäfer der Schweiz. Centre Suisse de Cartographie de la Faune (CSCF), Neuchatel.

Marshall, E.J.P., Brown, V.K., Boatman, N.D., Lutman, P.J.W., Squire, G.R., Ward, L.K., 2003. The role of weeds in supporting biological diversity within crop fields. Weed Res. 43, 77-89.

Mosimann, C., 2002. Diversity of ground beetles (Coleoptera: Carabidae) in relation to habitat age. Diploma Thesis. University of Bern.

Müller, C.B., Brodeur, J., 2002. Intraguild predation in biological control and conservation biology. Biol. Contr. 25, 216-223.

Nelemans, M.N.E., 1987. On the life-history of the carabid beetle Nebria brevicollis (F.). Neth. J. Zool. 37, 26-42.

Nentwig, W., 2000. Die Bedeutung von streifenförmigen Strukturen in der Kulturlandschaft. In: Nentwig, W. (Ed.), Streifenförmige ökologische Ausgleichsflächen in der Kulturlandschaft: Ackerkrautstreifen, Buntbrache, Feldränder. Agrarökologie, Bern, pp. 11-40.

Östman, Ö., 2005. Asynchronous temporal variation among sites in condition of two carabid species. Ecol. Entomol. 30, 63-69.

Östman, Ö., Ekbom, B., Bengtsson, J., 2003. Yield increase attributable to aphid predation by ground-living polyphagous natural enemies in spring barley in Sweden. Ecol. Econ. 45, 149-158.

Pearson, D., Knisley, C.B., 1985. Evidence for food as limiting resource in the life cycle of tiger beetles (Coleoptera: Cicindelidae). Oikos 45, 161-168.

Powell, W., Dean, G.J., Dewar, A., 1985. The influence of weeds on polyphagous arthropod predators in winter wheat. Crop Prot. 4, 298-312.

Purtauf, T., Dauber, J., Wolters, V., 2005a. The response of carabids to landscape simplification differs between trophic groups. Oecologia 142, 458-464.
Purtauf, T., Roschewitz, I., Dauber, J., Thies, C., Tscharntke, T., Wolters, V., 2005b. Landscape context of organic and conventional farms: influences on carabid beetle diversity. Agric. Ecosys. Environ. 108, 165-174.

Sato, T., Shinkaji, N., Amano, H., 2004. Effects of larval density on larval survivorship and imaginal fecundity of Dacne picta (Coleoptera: Erotylidae). Appl. Entomol. Zool. 39, 591-596.

Schmidt, M.H., Lauer, A., Purtauf, T., Thies, C., Schaefer, M., Tscharntke, T., 2003. Relative importance of predators and parasitoids for cereal aphid control. Proc. Roy. Soc. Lond. B 270, 1905-1909.

Siemann, E., Haarstad, J., Tilman, D., 1999. Dynamics of plant and arthropod diversity during old field succession. Ecography 22, 406414

Sota, T., 1985. Limitation of reproduction by feeding condition in a carabid beetle, Carabus yaconinus. Res. Pop. Ecol. 27, 171-184.

Symondson, W.O.C., Glen, D.M., Ives, A.R., Langdon, C.J., Wiltshire, C.W., 2002. Dynamics of the relationship between a generalist predator and slugs over five years. Ecology 83, 137-147.

Thiele, H.U., 1977. Carabid Beetles in their Environments. Springer, Berlin.

Thies, C., Tscharntke, T., 1999. Landscape structure and biological control in agroecosystems. Science 285, 893-895.

Thomas, C.F.G., Parkinson, L., Griffiths, G.J.K., Fernandez Garcia, A., Marshall, E.J.P., 2001. Aggregation and temporal stability of carabid beetle distributions in field and hedgerow habitats. J. Appl. Ecol. 38, $100-116$.

Tilman, D., 1990. Constraints and tradeoffs: towards a predictive theory of competition and succession. Oikos 58, 3-15.

Wallin, H., Chiverton, B.S., Ekbom, B.S., Borg, A., 1992. Diet, fecundity and egg size in some polyphagous predatory carabid beetles. Entomol. Exp. Appl. 65, 129-140.

Wise, D.H., 1979. Effects of an experimental increase in prey abundance upon reproductive rates of two orb-weaving spider species (Araneae: Araneidae). Oecologia 41, 289-300.

Zangger, A., Lys, J.-A., Nentwig, W., 1994. Increasing the availability of food and the reproduction of Poecilus cupreus in a cereal field by stripmanagement. Entomol. Exp. Appl. 71, 111-120. 